\title{
MADE IN BRAZIL: ENTRE OS LAÇOS DAS MIGRAÇÕES NA IDENTIDADE DA MÚSICA BRASILEIRA DOS ANOS 1970
}

\section{MADE IN BRAZIL: BETWEEN THE TIES OF THE MIGRATIONS IN THE BRAZILIAN MUSIC IDENTITY ON THE 70'S}

\author{
Jackson Gil Ávila \\ Doutorando em Ciências da Linguagem pela Universidade do Sul de Santa Catarina \\ E-mail: silegil@gmail.com
}

\section{Jussara Bittencourt de Sá}

Doutora em Literatura/ Letras pela Universidade Federal de Santa Catarina

Professora do Programa de Pós-Graduação em Ciências da Linguagem da Universidade do Sul de Santa Catarina E-mail: jussara.sa@unisul.br

\section{RESUMO}

O presente artigo procuramos refletir sobre as migrações na identidade musical brasileira dos anos 1970. Nossa pesquisa focaliza artistas que fizeram parte do movimento Made in Brazil e das associações que foram estabelecidas com o mercado fonográfico e com a televisão, mais especificamente as novelas e suas trilhas sonoras. Como recorte para estudar o movimento Made in Brazil, elegemos os cantores Fábio Júnior (Mark Davis e Uncle Jack), Chrystian e Michael Sullivan, além do grupo musical Pholhas. O objetivo é analisar como se construiu a identidade musical estrangeira de cada artista e quais os desdobramentos que se estabeleceram na carreira de cada um, após o fim do movimento. Esta pesquisa configura-se como um estudo de caso, e a análise desenvolvida tem como base os pressupostos da micro e da macro análise. As reflexões teóricas aportam-se em estudos sobre nação, identidades, migrações e indústria cultural, além de autores que possibilitaram a caracterização histórico-social da época destacada, enfatizando a música brasileira e o movimento analisado. Destacamos que o movimento Made in Brazil foi, em seu tempo, exitoso, na medida em que soube utilizar da indústria cultural para estabelecer um contato estreito com o público e, assim, promover os artistas e suas músicas, bem como as trilhas sonoras das telenovelas; colocando em cena os "estrangeiros brasileiros".

Palavras-chave: Made in Brazil. Telenovela. Indústria cultural. Identidades. Migrações.

\section{ABSTRACT}

In this paper, we seek to ponder about the migrations on the Brazilian's musical identity on the 70's. Our research focuses artists who has taken part in the movement Made in Brazil, and the associations that were established with the phonographic market and the television, more 
specifically: the TV soap operas and their soundtracks. As an excerpt to study the Made in Brazil, we elected the singers Fábio Júnior (Mark Davis and Uncle Jack), Chrystian and Michael Sullivan, and the musical group Pholhas. The objective is to analyze how the foreign musical identity of each artists was constructed, and what are the developments that have established in the career of each artist, after the movement's end. This research is configured as a case study, and the analysis has its base in the presuppositions of the micro and macro analysis. Nation, identities, migrations and cultural industry are the theoretical reflections, and authors that allowed the historical-social characterization of the pointed out epoch, emphasizing the Brazilian music and the analyzed movement. We make stand out that the movement Made in Brazil was successful in its time, as long as it managed to utilize the cultural industry to establish a strict contact with the public, promoting the artists and their songs, as well as the soundtracks of the TV soap operas; spotlighting the "Brazilian foreigners".

Keywords: Made in Brazil. TV soap opera. Cultural industry. Identities. Migrations.

\section{INTRODUÇÃO}

No presente artigo lançamos nosso olhar para os anos 1970, mais especificamente, para um momento cultural no qual surgiu no cenário musical brasileiro um movimento curioso, formado por artistas que optaram por gravar músicas em inglês, que viria a ser denominado de Made in Brazil. Esse movimento insere-se com linhas peculiares no desenho da história da música no Brasil. Essa 'onda' oportunizou cantores e grupos musicais nacionais brasileiros um lugar nas paradas de sucesso e, com isso, alcançaram enorme vendagem de discos e reconhecimento junto ao público. Assim, com intuito de estudar o Made in Brazil, nossa pesquisa optou por investigar quatro artistas que tiveram grande repercussão durante o movimento aqui destacado e que, após o final da tendência continuaram nas paradas e fazendo sucesso junto ao público: os cantores Fábio Júnior (Mark Davis e Uncle Jack), Chrystian (da dupla sertaneja Chrystian e Ralf) e Michael Sullivan (integrante do conjunto The Fevears e, mais tarde, da dupla de compositores Sullivan e Massadas), além do grupo musical Pholhas.

O estudo sobre o movimento e os desdobramentos alcançados pelos artistas na década em questão ensejou também um levantamento sócio-histórico dos anos 1970, bem como uma análise do poder de penetração da indústria cultural na sociedade da época, a partir de sua representação através da televisão, mais especificamente a Rede Globo; a força de persuasão das telenovelas; e a 
novidade que chegava ao mercado, juntamente com esse produto cultural, as trilhas sonoras. A pesquisa encontra-se ancorada em teóricos que versam sobre a identidade, mais precisamente, diante da contemporaneidade e da globalização, que nos deram um suporte para a análise.

\section{A MÚSICA POPULAR BRASILEIRA: NA TRILHA DE SUA HISTÓRIA}

As raízes da música brasileira, segundo Albin (2003), remontam-se aos nossos primeiros habitantes, que inclusive já fabricavam seus instrumentos musicais; uma experiência musical que se dava nos ritos e celebrações e que teria sido modestamente transmitida à cultura brasileira. $\mathrm{O}$ autor ainda aponta que a primeira manifestação musical no Brasil (mais do que brasileira) seria aquela religiosa, trazida pelos colonizadores portugueses e que servia como meio de catequização dos índios, infundindo-lhes a religiosidade através da mística do canto.

Nos três primeiros séculos da colonização brasileira, afirma o pesquisador, as formas musicais existentes eram bem isoladas e definidas: de um lado, o canto para os rituais indígenas e o batuque dos escravos; do outro, as cantigas dos europeus colonizadores, originárias dos burgos medievais dos séculos XIII e XIV. E ainda havia o hinário religioso católico dos padres e as fanfarras militares dos exércitos portugueses aqui aquartelados.

A música popular verdadeiramente brasileira, afirma Albin, surge a partir do século XVII, quando ela se dessacraliza, deixando as casernas, as igrejas e a ordem unida, e mundaniza-se; ganhando as rodas públicas. A consolidação da música brasileira seria, então, contemporânea do aparecimento das cidades, ao mesmo tempo em que a música de raiz popular, assim como outras manifestações dos humildes, vai ser reprimida pelas elites, vista como estrategicamente inconveniente, insolente e ditadora de normas e costumes. Já na metade do século XIX, afirma Albin (2003), há dois gêneros muito populares: o lundu-canção e a modinha, considerada um canto urbano e branco, de salão; de caráter lírico e sentimental.

No entanto, as bases do que é hoje considerada a música popular brasileira, conforme o autor, começam a se formar na segunda metade do século XIX, devido à demanda por novas formas de lazer ou por uma produção cultural, em virtude do surgimento das cidades. Aproximadamente em 1875, surge outro gênero musical brasileiro, o maxixe; e, em fins do século XIX, essa dança chega ao teatro de revista e aos clubes carnavalescos, surgindo o maxixe cantado. Já a partir das últimas décadas desse século, o teatro de revista passa a ser o grande centro consumidor e também irradiador da nossa música popular. E ainda nos últimos anos desse século, organizam-se as sociedades recreativas e os blocos carnavalescos, oriundos na integração da população mestiça à sociedade. 
É na passagem para a década de 1930, segundo o autor, que tem início o que se chamou de Era de Ouro da MPB, a partir de duas modificações essenciais ao crescimento da música popular: a mudança do sistema de gravação mecânica para gravação elétrica e o aparecimento e disseminação do rádio, que foi utilizado como veículo de integração nacional. Já no começo dos anos 1950, época na qual o rádio ainda continuava em evidência e elegia seus reis e rainhas, surge o samba-canção, com características orquestrais e melódico-harmoniosas latino-americanas. $\mathrm{O}$ final dessa década marca ainda o aparecimento da Bossa Nova, tida inicialmente como um novo jeito de cantar samba, sob a influência do jazz, abordando em suas letras temas leves e descompromissados.

Mas também era o momento da Jovem Guarda, que inclusive transformou-se em estilo de vida aos segmentos da sociedade jovem de consumo. Foi também a época dos grandes festivais e dos musicais de auditório na Rede Record de Televisão, além de apresentar nossos primeiros roqueiros. Já a década de 1970, segundo o autor, é o momento de efervescência das canções de protesto, bem como de resgate do samba e da evocação dos gêneros nordestinos, além da afirmação do tropicalismo, que surgira no início da década anterior. E é justamente sobre esse recorte da história da música brasileira que nos debruçaremos para dar continuidade ao nosso estudo.

\subsection{NA FAIXA DOS ANOS 1970}

A década de 1970 desenhou-se como um momento em que os brasileiros se encontraram diante de grandes desafios e de dilemas existenciais

Do ponto de vista sócio cultural, o tempo também foi de grandes mudanças e de ruptura comportamental, capitaneada pelo movimento hippie. Impulsionados pelo advento da pílula, pregou-se o sexo livre, independente de gênero, não se levando em conta se havia ou não amor. As drogas ocuparam seu espaço, em suas mais variadas manifestações, fazendo, muitas vezes, parte da rotina diária da juventude. Na época, o movimento feminista embrenhava-se na busca efetiva de mais direitos da mulher. Um outro grupo, até então minoritário, que resolveu mostrar a cara foram os homossexuais. Além disso, o cuidado com o corpo também ganhou propulsão, bem como a moda. E, para os corpos ficarem perfeitos, surgiu a onda de fazer ginástica e praticar esportes. O tempo é de discoteque; de John Travolta e seus Embalos de Sábado à Noite, de Sônia Braga e Dancing Days.

Artisticamente, segundo Bahiana (2006), os anos 1970 foram uma década de experiências com muito pouca intermediação, não importando se havia registro de memória; a captura do 
momento fugaz, em toda sua plenitude, era privilégio de cada um. Para a autora, a década aparece como a raiz das delícias e dos horrores que o novo século traria: o trinfo do corpo, o terror político, fartura e escassez.

\subsection{AGULHA NA MÚSICA POPULAR BRASILEIRA DOS ANOS 1970}

Os anos 1970 representaram uma época de instabilidade para o cancioneiro do país.

A relação gravadora/mídia se tornava uma instância poderosa, acessível a poucos eleitos: nomes já consagrados ou figuras forjadas na própria gravadora para atingir o grande público. Nenhuma gravadora se arriscava em lançamento incerto, devido à imensa crise financeira que atingiu o Brasil, a partir de 1973, e corriam riscos apenas com os conhecidos medalhões, que valessem tais despesas e apostas: lançamentos massificados e baratos, na forma de sucesso padrão, além do aproveitamento das matrizes estrangeiras. Seria a lei que dividia os artistas em populares e de elite; aqueles de vendas e aqueles de prestígio. Para Napolitano (2005), até o final da década, a corrente principal da música popular brasileira seria formada pelos "monstros sagrados" da MPB e por artistas mais identificados com outros gêneros, como alguns roqueiros (Rita Lee e Raul Seixas) e sambistas (Martinho da Vila, Beth Carvalho e Paulinho da Viola), A trilha sonora da época seria o encontro de três conceitos: o nacional popular (MPB), a cultura popular (samba e gêneros nordestinos) e as subculturas juvenis (o pop como catalizador das vanguardas experimentais).

A música brasileira se popularizou e atingiu um público mais jovem, alavancada pelo surgimento das rádios FM e a popularização da TV e dos LPS de telenovela. Segundo Autran (2005), devido ao massacre que a música popular brasileira sofreu, abafada pela repressão, foi necessário a criação de novos produtos fonográficos para atender a um mercado em acumulada expansão. No final da década, nosso mercado era o sexto do mundo, mas a descaracterização da arte brasileira resultava numa importação maciça de tapes e matrizes estrangeiras e pela imposição de imitações, colocando em cena o projeto Made in Brasil.

\subsection{A INDÚSTRIA CULTURAL: ALGUNS PONTOS}

Seria difícil entender o processo de migração da identidade musical que se deu no Brasil dos anos 1970, sem se não direcionarmos parte dos nossos estudos para a dimensão dada ao cenário artístico da época, a partir do advento da indústria cultural, que nos colocou diante das novas tecnologias, a acelerada expansão dos mercados e a globalização. Conforme Benjamin 
(1993), a obra de arte, em sua essência, foi sempre reprodutível. Mas, na era da reprodutibilidade técnica, perde sua aura. E, ao mesmo tempo em que se facilita ao espectador o acesso, atualiza-se o objeto reproduzido, relacionando-se diretamente com os movimentos de massa e contribuindo na renovação da humanidade e na liquidação do valor tradicional do patrimônio cultural. E essas características teriam origem na nossa experiência cultural pós-moderna que, segundo Chauí (2006), é volátil e efêmera, desconhecendo qualquer sentido de continuidade e se esgotando no presente fugaz

Nesse processo, a indústria se adapta aos desejos por ela evocados. Senso crítico e competência acabam por serem banidos como sinais de superioridade; ao mesmo tempo em que a cultura, democrática, divide os seus privilégios entre todos. Na indústria cultural, o indivíduo não deve contestar a sua inserção no universal, pois ele se reduz a uma identificação imediata dentro do todo. A obra de arte se adequa por completo à necessidade, substituindo o valor de uso pelo de troca. Faz-se apologia das mercadorias sempre iguais sob etiquetas diferentes, disfarçadas pela aparência de uma possibilidade de escolha. O mercado é o delimitador da autoridade dos produtores de cultura, que obtém sua força a partir do êxito junto ao público, evidenciado nos números da audiência.

E tal dependência faria sentido porque a TV não exige mobilidade nem alfabetização e consegue hipnotizar o telespectador, apresentando modelos comportamentais. A TV, afirma Tesch (2006), manipula através de uma gramática do discurso midiático que requer do consumidor uma certa familiaridade para que possa ganhar legitimidade e interatividade, institucionalizando-se como espaço de mediação social. E essa facilidade de atingir ao público, seja através de uma temática que aborda discussões socioculturais, seja pela força de sua inserção no âmbito da produção, circulação e consumo de bens materiais, leva à concentração, nela, da maioria das verbas publicitárias.

Esses consumidores acabam sofrendo com a dispersão da atenção e com a infantilização. Institui-se, assim, o mercado cultural, onde a cultura de massa se apropria das obras culturais para consumi-las numa lógica de consumo permeada pela futilidade, pela banalização e pelo simulacro. No final, tudo acaba por se reduzir à questão do gosto, da aversão, dos sentimentos. A sociedade baseada na indústria moderna, segundo Debord (1997), objetiva o espetáculo, no qual o fím não é nada e o desenrolar é tudo, e o único resultado a ser alcançado é o próprio espetáculo. Para o autor, a dominação da economia sobre a vida social acarretou a evidente degradação do ser para o ter; e a fase atual, na qual a vida está totalmente caracterizada pelos resultados acumulados da economia, há um deslizamento generalizado do ter para o parecer, ao mesmo tempo em que a realidade individual tornou-se social. 
O espetáculo, afirma Debord, é uma atividade especializada que responde por todas as outras, representando a diplomacia de uma sociedade hierárquica na qual outra fala é banida. $\mathrm{O}$ espetáculo é constituído pelo fetichismo da mercadoria, no qual o mundo sensível é substituído por uma seleção de imagens que existe acima dele. A sociedade moderna é dominada mundialmente por um espetáculo de banalização, a representação espetacular do homem vivo na condição de identificado com a vida aparente sem profundidade, que deve compensar o estilhaçamento de estilos de vida e dos estilos de compreensão da sociedade. Conforme o autor, o reconhecimento e o consumo da mercadoria são uma pseudoresposta a uma comunicação sem resposta. A necessidade da imitação compensa a falta de representação de quem está à margem da existência.

E diante dessa realidade espetacular utilizada pela indústria cultural para alienar seu público alvo, a telenovela é um dos produtos a se destacar, em virtude de seu poderio de persuasão. Assim, em nosso estudo destinamos uma atenção especial a esse produto cultural para poder estabelecer um paralelo com o papel desempenhado pela telenovela na idealização do projeto Made in Brazil e na manutenção do sucesso desses artistas, através das trilhas sonoras.

\section{A TELENOVELA BRASILEIRA: LAÇOS E ENCARTES DE SUA HISTÓRIA}

A origem das telenovelas remonta ao romance-folhetim e as radionovelas Em 1950, ocorre o advento da televisão e cria-se um novo campo a ser explorado. No ano seguinte, a TV Tupi de São Paulo estreia a primeira telenovela: Sua Vida me Pertence, de Walter Foster. Em julho de 1963, vai ao ar a primeira telenovela diária, 2-5499 ocupado, na TV Excelsior, fazendo parte de uma estratégia de popularizar o canal e elevar a audiência na competição com a TV Tupi e a TV Record. A novidade seria também uma estratégia de marketing orientada pelo patrocinador, a Colgate-Palmolive no Brasil. Em 1964, O Direito de Nascer é um sucesso da tv, fazendo com que famílias mudem seus hábitos como o do horário de jantar para se postarem diante do televisor e acompanhar o drama de Albertinho Limonta e sua mãe. A hegemonia da telenovela a tornaria produto de concorrência entre as emissoras, decretando o fim de outros gêneros como o teleteatro e se torna a grande responsável pela elevação dos índices da audiência televisiva, o que a levou para o horário nobre.

A partir da virada dos anos 1960/1970, ocorre o momento de consolidação da televisão brasileira. O número de aparelhos nas casas mais que duplica em cinco anos, chegando a 10,2 milhões em 1975 e, em 1980, chegam a 19,6 milhões. O investimento publicitário também cresce vertiginosamente, alcançando 36,7\% em 1970, 42,7\% em 1976 e 51,6\% em 1982. Paralelamente a essa estrutura organizacional, surgem as inovações tecnológicas e gerenciais da produção, tendo a Rede Globo como mola mestra dessa propulsão. 


\subsection{AS LINHAS DA REDE: TV GLOBO}

Ao falar em novelas, não há como desenvolver um estudo sem destinar um lugar de destaque para a Rede Globo de Televisão e o papel que a mesma representa no processo de criação e difusão desse produto cultural tão valorizado junto ao telespectador brasileiro. Segundo Bolaño (2005), alguns fatores que influenciaram nesse sucesso, no início, foram: o fato de Roberto Marinho ser empresário da comunicação, a adequação do projeto aos interesses do regime militar e o capital investido pelo grupo Time-Life. A TV Globo, portanto, beneficia-se da nova fase de diretrizes do capitalismo brasileiro, no governo Castelo Branco, que buscam a integração do território nacional, para utilizar os modernos sistemas de comunicação na sua rede e aproveitar ao máximo os benefícios do acordo com a rede norte-americana.

Com o passar do tempo, o canal pertencente ao grupo Marinho mostra-se mais regular do que as concorrentes, mantendo três horários de novelas (19, 20 e 22h), fixando também o horário das 18 horas a partir de 1975. Nesse momento, também ocorre uma definição quanto ao número de capítulos e a duração ideal de uma obra, seis a nove meses, com 155 capítulos em média. Acontecem ainda mudanças na duração diária das novelas, passando de mais de uma hora para 40/45 minutos e, posteriormente, 50/60 minutos.

Mesmo tendo sofrido forte concorrência, ainda que por breves períodos, a dominação do mercado pelo canal de Roberto Marinho é constante. No ano de 2000, conforme Santos \& Caparelli (2005), num ranking por média de telespectadores, os 10 programas de maior audiência na TV brasileira eram todos da Rede Globo, sendo quatro programas de informação, três de ficção e três de shows de variedades. Dentre eles, o mais assistido foi uma telenovela que alcançou 67\% de audiência e 35 milhões de telespectadores.

Assim, a partir deste demonstrativo do poderio mercadológico da TV Globo, não poderíamos deixar de destacar em nossa pesquisa a telenovela enquanto produto cultural, visto que ninguém melhor do que o canal de TV do Grupo Marinho soube utilizar este produto em favor do seu domínio de mercado.

\subsection{A TELENOVELA: ENTRELAÇOS DA CULTURA}

A telenovela é um produto midiático que requer renovação constante nas suas produções que, por demandar a atenção dos telespectadores por vários meses, precisa lançar mão de estratégias e mecanismos que mantenham o telespectador envolvido com suas narrativas. A simbiose entre o telespectador e a obra que este acompanha diariamente, no mesmo horário, é 
tamanha que ele não percebe os padrões de comportamento que é forçado a adotar. As cenas que desfilam diante de seus olhos, conforme Ramos (1991), apresentam logotipos de serviços e produtos, embutidos nas relações de aventura e de amor. E, assim, enquanto o povo pensa que apenas acompanha a novela, é bombardeado por apelos consumistas.

A telenovela, uma narrativa produzida em escala industrial e marcada pelas fortes determinações empresariais e econômicas que as envolvem, vai receber assim uma padronização, na busca pelo padrão de qualidade, combinando aparato tecnológico e visual; o tratamento dado à narrativa, que vai reunir a técnica tradicional e a linguagem contemporânea; e o talento dos autores, diretores, atores e demais envolvidos nas produções. A emissora cria uma casta de autores consagrados, contratando-os por períodos longos e encomendando obras para os diversos horários. Os elencos fixos também são formados, reunindo grandes atores contratados com exclusividade; a fórmula que garante a TV Globo a hegemonia no mercado.

\subsection{AS TRILHAS SONORAS: TRAMAS EM "FIOS DE OURO"}

A popularidade da telenovela no Brasil foi acompanhada pelo sucesso de suas trilhas sonoras, a partir dos discos com temas de novelas que foram amplamente tocados nas emissoras de rádio e alcançaram ampla vendagem no país. O primeiro long-play de novela surgiu no mercado brasileiro em 1965, todavia a fórmula novela-trilha teria sido patenteada pela Rede Globo, que, a cada nova novela, lançava dois LPs, o nacional e o internacional. Inicialmente, através da gravadora Philips, depois é criada a gravadora Som Livre, que, a partir de 1971, passa a cuidar das trilhas sonoras das novelas da emissora. A confirmação de que a Rede Globo acertara mais uma vez, conforme Riguini (2004), viria em 1972, com a vinculação de dois grandes sucessos musicais internacionais as suas telenovelas: Rock-and-Roll Lullabay - com B. J. Thomas - na trilha sonora de Selva de Pedra; e Ben, com Michael Jackson, em Uma Rosa com Amor. Também na década de 1970, a Rede Globo contrata Walter Avancini para assumir seu departamento de teledramaturgia, e este convida o maestro Júlio Medaglia para implantar uma sonoplastia inteligente na TV brasileira. Em 1974, Guto Graça Mello assume a supervisão comercial da Som Livre, dando uma nova diretriz às trilhas sonoras das novelas, o que faz com que as vendagens aumentem consideravelmente. Em 1976, a trilha sonora de Estúpido Cúpido alcança a marca de um milhão de cópias vendidas.

A transformação da trilha sonora televisiva em mais um filão comercial, afirma Campedelli (2001), ocorreu com a modernização da TV Globo, a partir da criação de duas gravadoras, a Sigla e a Som Livre. Além disso, emplacar uma canção na trilha sonora de uma 
novela seria sinônimo de sucesso imediato para os artistas brasileiros, pela força da presença na vitrine diária que é o vídeo. Conforme Riguini (2004), além das vendagens e da audiência; muitas carreiras de artistas musicais brasileiros foram alavancadas graças às telenovelas. Vários intérpretes teriam alcançado o estrelato simplesmente porque suas canções fizeram parte de uma trilha sonora; além de outros que já estavam um tanto ofuscados e que tiveram as carreiras retomadas. Num espaço altamente competitivo, o disco de um artista que tenha uma música numa trilha sonora televisiva se beneficia de toda essa divulgação, atingindo mais facilmente os outros meios de difusão, que vão desde a programação das rádios aos espaços de destaques nas lojas. E os artistas do movimento Made in Brazil não pouparam esforços para conquistar o seu espaço dentro dessa realidade, lançando mão de qualquer artifício que lhes proporcionassem alcançar o que almejavam.

\section{MADE IN BRAZIL: RODANDO O MOVIMENTO TECIDO}

Uma das grandes marcas do mercado musical brasileiro dos anos 1970 foi o projeto ousado de determinados produtores e artistas nacionais que, literalmente, dominaram boa parte do mercado fonográfico e das paradas de sucessos, constituindo-se numa alternativa ao cenário, majoritariamente dominado pela música estrangeira. O movimento foi composto por falsos astros importados, com performances que enganaram o público. Compondo e cantando em inglês, eles evitavam um contato mais direto com os fãs, o que poderia colocar em risco a farsa.

O Movimento Made in Brazil, conforme Campos (2012), remete suas origens ao final dos anos 1950, quando o conjunto The Playings grava um LP de enorme sucesso pela gravadora RGE, sendo - na verdade - formado por Eloá, Lurdinha e Nadir. Outra ideia de sucesso segundo Barcinski (2014) foi o lançamento de Prini Lores, uma imitação do cantor norte americano Trini Lopez, que foi lançado no Brasil pela RGE antes do original, que continha sucessos como $L a$ Bamba. Já na década de 1960, surgiu um vasto número de bandas de garagem que adoravam tocar música anglo-americana: Jet Blacks, Jordans; Sunday, Konpha, Menphis e Lee Jackson.

Gravadoras chegaram a criar selos para lançar grupos Hits Brasil, como também ficou conhecido o movimento, como o Cast Box (Copacabana) e o Young (RGE). Segundo Campos, o Hits Brazil misturava a influência lírica italiana com a balada americana, fazendo canções mais românticas, com características de emotividade e tendo ingredientes próprios da cultura brasileira: nostalgia, emoção, amor e beleza melódica. Ainda segundo o autor, a contribuição para o sucesso teria vindo das domingueiras e dos pontos de encontro nas festinhas na casa de amigos, embaladas por disc-jóqueis, numa época em que não havia grandes opções de lazer para a juventude. As 
domingueiras aconteciam nos badalados clubes da época: o Esporte Clube Pinheiros, o Clube Atlético Paulistano e a Hebraica, por exemplo; embaladas por conjuntos que se tornaram ídolos da juventude, dentre eles Rubber Souls, Loupha, Colt 45 e Mustangs. Outro fator contribuinte seriam os disc-jóqueis das rádios, que assistiam aos shows e ficavam por dentro das novidades.

Ainda segundo Campos (2012), com a onda Beat ${ }^{l}$ no auge e com a influência do rock britânico, cantar em inglês era moda, sendo que alguns conjuntos faziam sucesso com músicas internacionais, que normalmente demoravam a chegar ao país, enquanto outros preferiam aquelas inéditas de seu repertório; sendo também um ingrediente a rivalidade entre os grupos. Cada um deles era especialista no repertório de um conjunto estrangeiro, e nenhum invadia a área do outro. Os grupos de destaque nesse momento foram: Sunday, Watt 69, Konpha, Menphis e Lee Jackson.

Entretanto, vai ser nos anos 1970 que cantar em inglês vira um projeto, quando as gravadoras acabam por descobrir um novo filão musical, jovens artistas que compunham em inglês. E, enxergando a oportunidade mercadológica, alguns empresários interessados em conseguir espaço no mercado internacional lançaram artistas que vieram a alcançar grande sucesso. Hélio Costa Manso, conhecido durante o movimento pelo pseudônimo de Steve McLean; foi, segundo Campos, figura importante para o movimento Hits Brazil, por ter criado uma grande coleção de astros internacionais cantando em inglês nas trilhas das telenovelas, enquanto produtor musical, como: Terry Winter, Dave MacLean, Malcolm Forest, Patrick Dimon e um dos principais artistas do movimento, Morris Albert, que gravou a canção "Feelings", que está dentre as mais regravadas em todos os tempos, com versões inclusive de astros da música internacional, como Frank Sinatra e Julio Iglesias. A balada alcançou o topo das paradas em 52 países, vendendo mais de três milhões de cópias em 1975, e permaneceu 32 semanas na parada das 100 mais da revista Billboard. Outro fenômeno foi o grupo musical Liht Reflections, que, em 1972, vendeu um milhão de compactos da música Tell me once again.

Outro produtor musical que teria feito parte da espinha dorsal do movimento seria, conforme Campos, Toninho Paladino, dono da Eletroarte, um ponto de reuniões da juventude, na rua Augusta, onde os disc-jóqueis compravam os discos para tocar nas rádios e boates. Ele recebia na loja os sucessos norte-americanos bem antes das gravadoras, uma lacuna que poderia ser de seis meses. Era a oportunidade, então, de se criar os Cover Virgin, uma versão parecida com a internacional. Até mesmo os artistas tinham nomes parecidos aos originais. Jorge Cayon Gadia também é destacado por Campos (2012). Como diretor da divisão de shows da rede Tupi, comandava programas como o de Hebe Camargo, Flavio Cavalcanti, Chacrinha, J. Silvestre e Almoço com as estrelas; e sua participação no movimento em destaque teria acontecido a partir do convite feito por Paladino para gravar algumas músicas em inglês e testar o mercado. A partir da parceria, surgem sucessos como: Sunday, Lee Jackson e Mark Davis. 
Algo que ajudou e muito os 'falsos gringos' a se tornarem tão populares foi o casamento com as trilhas sonoras das telenovelas. Naquele contexto, os artistas ficavam nos corredores das gravadoras para obter informações sobre os personagens que ganhariam o tema para, então, compor a música e o arranjo; tudo em um ou dois dias. Quanto ao idioma, as letras eram compostas por quem não sabia nada de inglês e corrigida por quem tinha alguma noção sobre a língua. Alguns, inclusive, evitavam o contato com o público e cantar ao vivo para que a farsa não fosse percebida. E a ideia deu certo, visto que as gravações vendiam milhares de LPs e compactos, gerando grandes sucessos que marcaram época e ficaram no imaginário social.

Alguns dos artistas de sucesso da época continuaram em evidência, mesmo com o fím do movimento, assumindo outras identidades musicais. Fábio Júnior foi um deles; iniciou sua carreira formando um trio musical com seus dois irmãos e também entrou para a dramaturgia, participando de teleteatros e de especiais na TV Cultura. Entretanto, em 1973, passou a integrar como crooner a banda Uncle Jack. De 1974 a 1975, com o fim da banda, gravou um LP e vários compactos em inglês, agora com o pseudônimo de Mark Davis. O sucesso da canção Don't let me cry, incluída na trilha sonora da telenovela da rede Tupy $A$ Barba Azul, foi tamanho que, no ano seguinte, a gravadora MGM lançou o segundo compacto e, em seguida, um LP do artista.

O cantor Chrystian, que começou sua carreira artística aos seis anos, inclusive tendo seu próprio programa mirim, foi outro importante destaque do movimento. Em 1973, gravou o primeiro de uma série de temas de novela, em inglês, Please Don't say goodby", que fez parte da trilha sonora de Cavalo de Aço; ficando dezenove semanas em primeiro lugar nas paradas de sucesso. A discografia de Chrystian, enquanto astro solo do movimento Made in Brazil, inclui um LP e um compacto duplo, pela gravadora Blue Rock Records, em 1973, e um LP gravado em 1976.

Michael Sullivan, que começou como crooner e depois integrou conjuntos de sucesso como Renato e Seus Blue Caps, também obteve grande destaque. O artista compôs e gravou a canção My Life, que fez parte da trilha sonora da novela O Casarão. O compacto que incluía a canção vendeu mais de um milhão de cópias e lhe rendeu um disco de diamante. Em 1977, gravou Sorrow, incluída na novela Locomotivas.

Outro grande sucesso foi o conjunto Pholhas, criado no início de 1969, e que iniciou a carreira fazendo covers de bandas dos Estados Unidos e da Inglaterra. Entre 1969 e 1972, realizam diversos bailes de sucesso, já possuindo uma legião de fiéis admiradores. Quase todas as canções gravadas pela banda, afirma Campos (2012), eram compostas pelos próprios integrantes da banda. Em seu primeiro disco, as canções My Mistake e Pope possuem letras simples, retocadas por amigos professores de inglês. Mas para o primeiro LP, o trabalho seria muito maior, e o grupo cria seu próprio método de compor, ao juntar frases encontradas no livro Inglês Sem Mestre, que 
ensinava a língua através de frases feitas e acompanhadas de tradução. Esse primeiro disco, gravado em 1972, começa a fazer um grande sucesso com My Mistake, em 1973, vendendo 400.000 cópias.

Em seguida, é lançado seu primeiro LP, "Dead Faces”, trazendo como sucessos, além da canção já consagrada, She Made Me Cry e I Never Did Before; chegando ao primeiro lugar de vendas, pela RCA Victor. O segundo álbum é "Forever" (1974). Em 1975, lançaram o álbum "Hojas" na Espanha e em toda América do Sul, que lhes rendeu mais um disco de ouro. Nesse mesmo ano, sai um LP que leva o título "Phollas", trazendo os sucessos Get Back e My Sorry.

Com o fim do movimento, a partir da década de 1980, Fábio Júnior assumiu a faceta romântica e de galã de novelas, alavancando uma carreira que o levou a ter um programa de televisão. Chrystian, em parceria com o irmão Ralf, formou uma duple sertaneja de grande sucesso, considerada por muitos a mais afinada do país. Michael Sullivan, após fazer parte do grupo The Feavers, alcançou as paradas com suas composições em dupla com Paulo Massadas, nas vozes dos mais variados artistas. Já os Pholhas optaram por seguir a carreira cantando em inglês e, embora não estejam tão presentes na mídia, chegaram a uma carreira de 40 anos de sucesso, mantendo um público cativo.

\subsection{A IDENTIDADE MUSICAL BRASILEIRA: FAIXAS EM LINHAS TRAVESTIDAS}

Estudar o movimento Made in Brazil é um processo que nos leva a compreensão de um projeto que alcançou amplo destaque dentro do cenário musical brasileiro. Os falsos gringos alcançaram tal simbiose com o público, chegando a milhares de discos vendidos e uma década de

sucesso. É claro que esse casamento só foi possível devido a alguns mecanismos que possibilitaram essa aproximação entre os artistas e o público. E, dentre esses fatores, não poderíamos deixar de destacar o imperialismo cultural norteamericano que se instalava no Brasil e com ele o advento do inglês; o poderio da indústria cultural que se espalhava pelo país, com a disseminação da televisão nos lares brasileiros; o papel de protagonista que a Rede Globo de Televisão assumiu no cenário televisivo nacional, estendido ao mercado fonográfico, com a criação da gravadora Som Livre; e o surgimento de um novo produto cultural, a telenovela, que muito contribuiu para todo esse sucesso, com suas trilhas sonoras.

Outra faceta importante a ser enfatizada centraliza-se no momento histórico e artístico da década em questão, caracterizado por uma pluralidade artística e, ao mesmo tempo, um certo silenciamento musical que permitiu o surgimento e a permanência no auge de um movimento artístico tão peculiar. Foi preciso também entender o momento político brasileiro, suas influências 
na arte e, mais precisamente, na música brasileira, para poder compreender de que forma a busca pela modernização do país e - ao mesmo tempo - o cenário musical construído pela censura estabeleceram um ambiente propício para a criação do projeto Made in Brazil.

No século XX, a identidade musical brasileira também se permitiu uma diversidade maior, assumindo um caráter regional, com o advento da música nordestina, criando uma faceta mais jovial, com o surgimento da Jovem Guarda. Também se caracterizou por uma certa elitização, como ocorreu a partir da Bossa Nova. Já nas décadas de 1960 e, mais precisamente 1970, nossa música vai caracterizar-se por uma pluralidade criadora, em tempos de pouca liberdade. Esse pluralismo musical permitiu não só o advento, mas também a permanência em evidência durante uma década, desse projeto tão sui generis.

O movimento Made in Brazil foi um nicho de mercado dos anos 1970, uma década de grande relevância no cenário político e social brasileiro, $\mathrm{O}$ momento histórico era de repressão e censura, conflitos e exílios. Os grandes nomes da MPB estavam exilados, a música brasileira dos anos 1970 perdeu sua fronteira rítmica. O único parâmetro era a possibilidade de mercado, o que determinava os eleitos e os excluídos. O poder de decisão estava na mídia, através das gravadoras, e o mercado era acessível a poucos. Na maioria das vezes, a opção era por lançamentos baratos e massificados, que seguiam um padrão de sucesso. A programação musical televisiva, que tanto destaque obtivera na década anterior, entrou em declínio e teve seu espaço tomado pelas telenovelas. A seleção do que viria a ser gravado começou a seguir as encomendas da teledramaturgia ou a se aproveitar dela, configurando-se um casamento que iria viabilizar grandes sucessos.

O tempo foi também de massificação da música, com o surgimento das rádios FM e a disseminação da televisão. Além disso, diversificava-se o seu público, chegando aos jovens. E atingia-se também a família, a partir das telenovelas diárias que reuniam todos os dias no mesmo horário os familiares diante do aparelho de TV para acompanhar o romance do casal principal ao som de uma balada romântica internacional; pelo menos era o que parecia. Descoberta como um produto mercadológico extremamente rentável, a trilha sonora passa a ser a soma do trabalho de muitos profissionais: encaixando as canções no perfil dos personagens, criando esses a partir das canções, e encomendando temas de abertura que refletiam as características da trama ou que facilitavam ao público a absorção do enredo. Um trabalho conjunto de produtores, diretores, autores e sonoplastia; que vão selecionar artistas que as gravadoras querem lançar ou aqueles que precisam ser divulgados pela indústria fonográfica. O critério menos levado em conta era o artístico, mas o resultado era garantido: carreiras alavancadas, intérpretes levados ao estrelato, artistas afastados da mídia que retomavam seus trabalhos. 
O movimento Made in Brazil um dos maiores beneficiados com essa união da indústria fonográfica com a trilha sonora das telenovelas. A partir do investimento pesado da indústria fonográfica na criação de falsos ídolos estrangeiros e da inclusão desses artistas nos discos das telenovelas. Os artistas Made in Brazil se transformaram num fenômeno da indústria do disco e das paradas de sucesso, o que gerou vendagens da casa de milhares de cópias, além de um público cativo. O movimento, a partir da união com as trilhas sonoras das novelas globais, consolidou-se como uma estratégia mercadológica que teve seu espaço por uma década; constituindo-se realmente em uma febre nacional, que começou com a produção de artistas que buscavam se passar por originais internacionais, que, segundo Barcinski (2014), levavam em média seis meses para chegar ao Brasil, mas uma ideia que deu certo, e foram muitos os artistas que ousaram travestir-se de estrangeiros para embarcar nessa onda musical, sempre tendo como forte aliados os discos de novela e a participação nos programas populares de auditório da época: Chacrinha, Bolinha, Carlos Imperial e Flávio Cavalcanti.

\section{CONSIDERAÇÕES FINAIS}

A música brasileira nos 1970 constituiu-se plural, dentre outros aspectos, porque se permitiu a negociação com o estrangeiro, um hibridismo que se deu pela influenciação rítmica, pelos modelos musicais e pelo domínio de uma parte do mercado. Tal panorama encontra linhas de seu desenho no projeto Made in Brazil. Neste, conforme sublinhamos, os artistas brasileiros, mesmo sem o domínio da língua, puderam negociar como fazer parte de uma identidade musical estrangeira, o que lhes possibilitou tamanho sucesso, até mesmo maior do que os artistas originais. E foi assim que o movimento seu território na música popular brasileira, utilizando-se da identidade globalizada sob um duplo aspecto: a possibilidade do público se apropriar da música estrangeira, que agora tomava conta de boa parte do mercado fonográfico nacional, principalmente a partir das trilhas internacionais; e o nicho artístico que permitiu aos artistas brasileiros, tendo trocado a identidade musical, permanecerem em evidência nas paradas de sucesso, junto ao público, o que também lhes possibilitou a liderança nas vendagens de disco.

A identidade musical dos artistas Made in Brazil nunca foi um problema junto aos fãs, porque o pertencimento se dava pelas canções, internacionais, independentemente da verdadeira identidade do artista. A dimensão midiática alcançada pelo movimento possibilitou números de vendagem estratosféricos justamente por que explorou a possibilidade de identificação cultural com a música estrangeira, novidade apresentada pela modernização do país e pela globalização, massificadas através da televisão, que chegava aos lares brasileiros. O que podemos perceber foi 
que os artistas do movimento se caracterizaram por uma identidade forjada na indústria cultural. Os 'ídolos internacionais' foram fruto de um acordo de cavalheiros entre o mercado fonográfico e a mídia televisiva. Esse filão de musical teve seu potencial logo percebido e aproveitado pelos executivos das gravadoras, os diretores de televisão e, é claro, os artistas. O sucesso teve suporte das telenovelas e suas trilhas sonoras, que levaram os artistas Made in Brazil diariamente para os lares do público brasileiro.

\section{NOTA}

\footnotetext{
${ }^{1}$ A geração Beat era formada por jovens intelectuais, principalmente artistas e escritores, que contestavam o consumismo e a falta de pensamento crítico, dentre outros temas.
}

\section{REFERÊNCIAS}

ALBIM, R. C. O livro de ouro da MPB: a história de nossa música popular de sua origem até hoje. Rio de Janeiro: Ediouro, 2003.

BAHIANA, A. M. Almanaque anos 70. Rio de Janeiro: Ediouro, 2006.

BARCINSKI, A. Pavões Misteriosos: 1974-1983: a explosão da música pop no Brasil. São Paulo: Três Estrelas, 2014.

BENJAMIN, W. A obra de arte na reprodutibilidade técnica. In: Lima, L. Costa (Org.). Teoria da Cultura de Massa. Rio de Janeiro, Paz e Terra, 1993, p.211.

BOLAÑO, C. Mercado Brasileiro de Televisão, 40 anos depois. In: BRITTOS, V. C. \& BOLAÑO C. R. S. (orgs.) Rede Globo: 40 anos de poder e hegemonia. São Paulo: Paulus, 2005. (Comunicação)

CAMPEDELLI, S. A Telenovela. São Paulo: Ática, 2001.

CAMPOS, F. C. de C. Hits Brasil: sucessos "estrangeiros" made in Brzil. São Paulo: Agbook/ Clube de Autores, 2012.

CHAUI, M. Simulacro e poder: uma análise da mídia. São Paulo: Editora Fundação Perseu Abramo, 2006.

DEBORD, G. A Sociedade do Espetáculo: comentários sobre a sociedade do espetáculo. Rio de Janeiro: Contraponto, 1997.

DIAS, M. T. Rede Globo e Indústria Fonográfica: um negócio de sucesso. In: BRITTOS, V. C. \& BOLAÑO C. R. S. (orgs.) Rede Globo: 40 anos de poder e hegemonia. São Paulo: Paulus, 2005. (Comunicação)

NAPOLITANO, M. MPB: totem-tabu da vida musical brasileira. In: Anos 70: trajetórias. São Paulo: Iluminuras: Itaú Cultural, 2005. 
RAMOS, R. Grã-finos na Globo: cultura e merchandising nas novelas. $3^{\mathrm{a}}$ ed. Petrópolis: Ed. Vozes, 1991.

RIGHINI, R. R. A Trilha Sonora da Telenovela Brasileira: da criação à finalização. São Paulo: Paulinas, 2004. (Coleção Comunicação - Estudos).

SANTOS, S. dos. \& CAPARELLI, S. Coronelismo, Radiodifusão e Voto: a nova face de um velho conceito. In: BRITTOS, V. C. \& BOLAÑO C. R. S. (orgs.) Rede Globo: 40 anos de poder e hegemonia. São Paulo: Paulus, 2005. - (Comunicação)

TESCHE, A. Gênero e Regime Escópico na Ficção Seriada Televisual. IN: DUARTE, E. B. \& CASTRO, M. L. D. de. (Orgs.) Televisão: entre o mercado e a academia. Porto Alegre: Editora Sulina, 2006. 